\title{
Safety and efficacy of transluminal balloon angioplasty in the prevention of vasospasm in patients with Fisher Grade 3 subarachnoid hemorrhage: a pilot study
}

\author{
J. Paul Muizelaar, M.D., Ph.D., Marike Zwienenberg, M.D., Nancy A. Mini, R.N., and Stephen T. Hecht, M.D. \\ Departments of Neurological Surgery and Radiology University of California, Davis, Davis, California
}

Recent advances in neuroradiology have made it possible to dilate human cerebral arteries that show vasospasm following aneurysmal subarachnoid hemorrhage (SAH), but the time window is short and the success rate for reversal of delayed ischemic neurological deficit (DIND) varies between $31 \%$ and $77 \%$. In a canine model of vasospasm, transluminal balloon angioplasty (TBA) performed on Day 0 (the day of aneurysm rupture) has been shown to completely prevent the development of angiographically demonstrated narrowing by Day 7; this effect is better than any pharmacological treatment for vasospasm thus far described.

The authors conducted a pilot trial to assess the safety and efficacy of TBA performed within 3 days post-SAH. Twelve patients with a very high probability of developing vasospasm (Fisher Grade 3) were included. Target vessels for prophylactic TBA were the internal carotid artery, $\mathrm{A}_{1}$ segment, $\mathrm{M}_{1}$ segment, and $\mathrm{P}_{1}$ segment bilaterally, the basilar artery, and the vertebral artery.

No patient developed DIND or more than mild vasospasm, according to transcranial Doppler criteria. At 3 months, seven patients made a good recovery, two patients were moderately disabled, and three patients died; one patient died because of a vessel rupture during TBA and two older patients died of medical complications associated with an already poor clinical condition at admission.

Compared with the results of large series reported in literature of patients with aneurysmal SAH, the results of this pilot study indicate an extremely low incidence of vasospasm and DIND after patients underwent prophylactic TBA. A larger, randomized study, however, is required to determine whether prophylactic TBA is efficacious enough to justify the risks.

Key Words * subarachnoid hemorrhage * cerebral vasospasm * transluminal balloon angioplasty * aneurysm

Almost half a century has passed since the original descriptions of cerebral vasospasm occurring after aneurysmal subarachnoid hemorrhage $(\mathrm{SAH})$; despite intense research into its cause and pharmacological treatment and prevention, only very modest gains have been made.[12] Worldwide nimodipine is the only drug used to prevent neurological deficit resulting from vasospasm.[1,15,21,24,38,39,44] A number of other drugs have failed in clinical trials,[3,9,17,18,23,31] and other drugs have had unacceptable side effects.[9,10,40,49] Because of the ineffectiveness of pharmacological agents, including nimodipine, in treating established narrowing of the large conducting vessels of the circle of Willis, mechanical treatment with transluminal balloon angioplasty (TBA) has recently been introduced.[4,6,7,11,13,14,19,20,25,29,32,36,42,43,50] However, the time window for performing TBA in patients with symptomatic vasospasm is short and is successful in reversing delayed ischemic neurological deficits (DINDs) in only 31 to $77 \%$ of the cases.[5,6,11,19] For the treatment of symptomatic vasospasm TBA appears to have a low complication rate.[11,19,30,37,46] In one of the largest series to date, Eskridge and Song[8] found vessel ruptures with fatal outcome in two (4\%) of 50 patients who underwent TBA for symptomatic vasospasm. In the series of 31 patients reported by Bejjani, et al.,[5] no severe complications were encountered. To undergo TBA the patient must be moved from the intensive care unit to the radiology unit during a time at when intensive monitoring and treatment are most critical. Studies in patients with severe head injuries have shown that the incidence of secondary events (such as low blood pressure, poor arterial oxygenation, hypo- or hypercapnia) increases considerably during periods when patients have to be moved out of the intensive care unit.[2] Because symptomatic vasospasm is extremely rare before Day 3 after SAH and treatment is clearly much less intensive during the first 3 days, this would provide an ideal time window in which to prevent vasospasm by using TBA. 
In a canine model of vasospasm, TBA performed on Day 0 has been shown to completely prevent the development of angiographically demonstrated narrowing on Day 7; this result was ascribed to the blood vessels becoming unresponsive to a large number of constrictive, as well as dilatory agents.[33] Because the preventive effect of TBA was better than any pharmacological agent used in the treatment of experimental vasospasm and because TBA can be performed at a time at which secondary insults are usually not yet important, we pleaded for a rapid investigation of the efficacy of performing preventive TBA in patients with aneurysmal SAH.[35] Thus, a pilot trial was conducted to assess the safety and efficacy of TBA that is performed within 3 days after aneurysmal SAH has occurred. A relationship between the amount and distribution of subarachnoid blood detected by computerized tomography (CT) scanning and the later development of cerebral vasospasm was found by Fisher and colleges:[12] in the presence of subarachnoid blood clots larger than $5 \times 3 \mathrm{~mm}$ (measured on the reproduced images) or layers of blood 1-mm or more thick in fissures and basal cisterns, severe spasm almost invariably followed. Because TBA is an invasive procedure and not without risk, we believed it was justified in a pilot study to perform such a procedure only in patients with a very significant chance (Fisher Grade 3 hemorrhage) of developing vasospasm.

\section{CLINICAL MATERIAL AND METHODS}

The Human Subjects Review Committee at the University of California, Davis, Medical Center approved this study. The experimental nature of this treatment was explained to patients and/or their families, and informed consent was obtained before performing the preventive TBA.

\section{Inclusion Criteria}

All patients with SAH from a ruptured aneurysm, with the presence of diffuse, thick clots in the basal cistern or hemispheric fissures (Fisher Grade 3) detected on a CT scan obtained within the first 2 days after SAH, were considered for enrollment. Patients were only included after surgical treatment of the ruptured aneurysm and any coincidental unruptured aneurysm when preventive TBA could be performed within 3 days postrupture. No angiographic evidence of vasospasm was demonstrated in any patients included in our sample prior to undergoing TBA. No age limits were set. Pregnancy was not a reason for exclusion. Patients in whom a postoperative angiogram demonstrated vasospasm underwent TBA but were not considered for inclusion in the prophylactic treatment group. To be included in the prophylactic treatment group, the patient had to undergo TBA in at least two of the three parts of the intracranial circulation (right and/or left carotid system and/or vertebrobasilar system), including the arteries directly leading to the ruptured clipped aneurysm.

\section{Surgical and Medical Management}

Within 2 days postrupture all patients underwent clipping of their aneurysms through the classic transsylvian approach described by Yasargil and Fox.[48] Postoperatively, all patients received nimodipine (60 mg every 4 hours or 30 mg every 2 hours). Other drugs were given only for specific indications. To achieve plasma levels of approximately $2.2 \mathrm{mg} / \mathrm{L}$, magnesium supplementation was also administered.[47] The patient's hematocrit level was maintained at between 30 and $35 \%$ by either hemodilution or infusion of packed red blood cells. Patients received ample fluids, including $500 \mathrm{ml}$ albumin every 24 hours, for prophylactic hyperdynamic therapy. No other plasma expanders were used.[45] For hypertensive therapy, phenylephrine (30-300 $\mu \mathrm{g} /$ minute) was used as necessary in case of DIND.

\section{Transluminal Balloon Angioplasty}

After surgery the patients in Cases 1 through 9 were allowed to wake up and we checked for any new neurological deficits. The patients in Cases 10 through 12 remained intubated for TBA immediately postsurgery. Patients were then taken to the angiography suite. First, a diagnostic transfemoral angiogram was obtained to check for adequate aneurysm clipping, patency of the parent vessel, and the presence of early vasospasm. In all patients arterial access was gained via a No. 6 French sheath (Pinnacle, Meditech, Watertown, MA) percutaneously placed in the femoral artery. A 100-cm, 5.8 French thin-wall guide catheter (model P5.8-NT-100-M-NS-0; Cook, Inc., Bloomington, IN) was advanced into the internal carotid artery (ICA) and vertebral artery (VA). A 4 X 10-mm, 0.1- $\mathrm{ml}^{3}$ occlusion balloon-type angioplasty balloon catheter (model NDSB 8501/20002; Interventional Therapeutics Corp., Fremont, CA) was coaxially advanced through the guide catheter and into the intracerebral circulation. Angioplasty target goals for the carotid circulation were the $\mathrm{A}_{1}$ segment of the anterior cerebral artery (ACA), the $\mathrm{M}_{1}$ segment of the middle cerebral artery (MCA), and the supraclinoid ICA. The VA target goals were the $\mathrm{P}_{1}$ segments of the posterior cerebral arteries (PCAs) bilaterally, the basilar artery (BA), and the ipsilateral distal VA. All angioplasty balloon manipulations were performed after the patient had undergone systemic heparinzation (5000-U bolus) and roadmapping. Angioplasty balloons were inflated to the vessel diameter with approximately $1 \mathrm{~mm}$ of balloon elongation. Inflation duration was 5 second.[7,8] Angioplasty was performed in all target arteries that could be entered along their entire lengths with flow-direction technique. Following the procedure an angiogram was obtained in all cases to evaluate the change in caliber and the presence of any vessel damage. 


\section{Diagnosis of Vasospasm and Delayed Neurological Deficit}

For Days 10 to 14 post-SAH, transcranial Doppler (TCD) ultrasonography was performed on all vessels comprising the circle of Willis. Cerebral vasospasm was graded by peak mean velocities, according to the scale shown in Table 1.[31]

\begin{tabular}{|cc|}
\hline \multicolumn{3}{|c|}{ TABLE 1 } \\
MEASUREMENTS USED IN THE TCD ULTRASONOGRAPHY \\
GRADNG OF CEREERAL YASOSPASM \\
\hline \hline Mean Blood Flow \\
Velocily (cmlsecond) & TCD Wasospasm Severity \\
\hline $150-200$ & mild \\
$200-250$ & moderate \\
$>250$ & severe \\
\hline
\end{tabular}

Any DINDs were thought to be due to vasospasm if they occurred between Days 3 and 14 after the SAH in a vascular distribution that was judged to be at risk (focal deficits for all vessels and/or a decline in the Glasgow Coma Scale score of 2 or more for midline vessels) and when there was no other discernible cause of deterioration such as postoperative hematoma, hydrocephalus, seizure, or metabolic derangement.[16,18] In patients with a suspected DIND, angiographic confirmation was specified. Outcome was assessed at 3 months ( \pm 2 weeks) by an experienced, blinded assessor using the Glasgow Outcome Scale (GOS).[22] Outcome rating was assessed by the operating surgeon only in cases of early unequivocal good outcome (that is, returned to former work prior to 3-month window).

\section{RESULTS}

Patient characteristics and results are outlined in Tables 2 and 3. Representative CT scans obtained in patients who fulfilled enrollment criteria and underwent TBA during the study period are shown in Fig. 1.

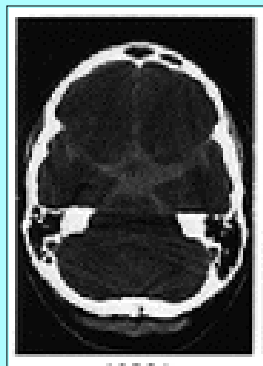

10001

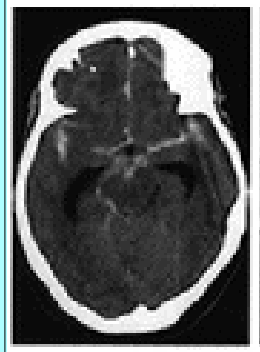

10007

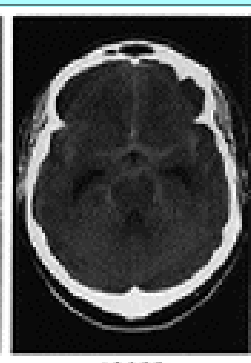

10002

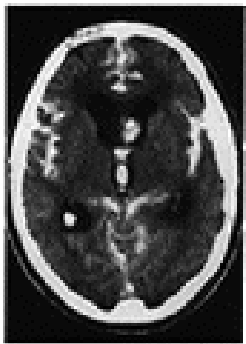

10008

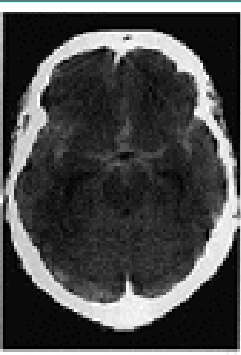

10003

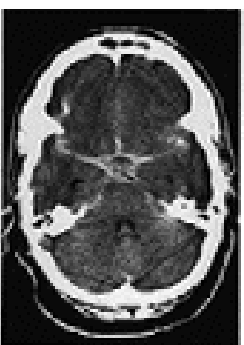

10000

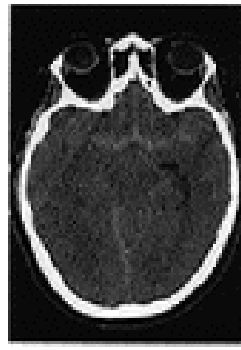

10004

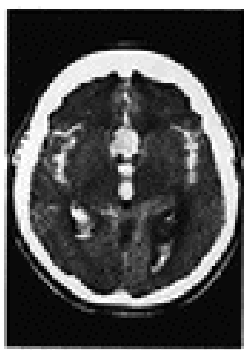

10010

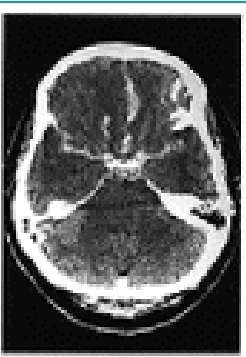

10005

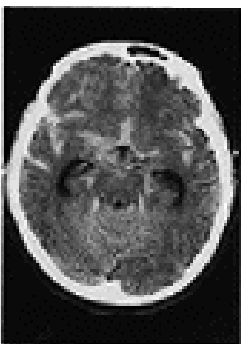

10011

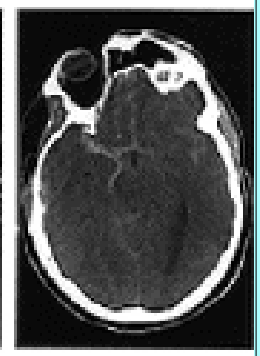

10006

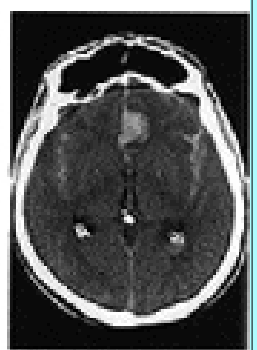

10012

Fig. 1. Representative CT scans obtained in patients treated with TBA. 10001 represents Case 1, 10002 Case 2, and so on.

Within a period of 10 months (6/97-3/98), a total of 12 patients were enrolled and underwent TBA as planned (study group [Cases 1-12], Table 2 and Fig. 1). During the same period we saw patients who also presented with a CT-documented Fisher Grade 3 SAH but were not included in our treatment group for various reasons (excluded group [Cases 13-19], Table 3). 
TABLE 2

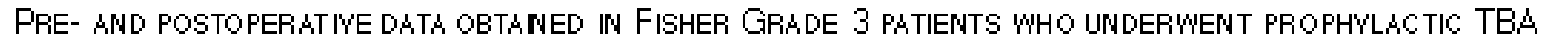

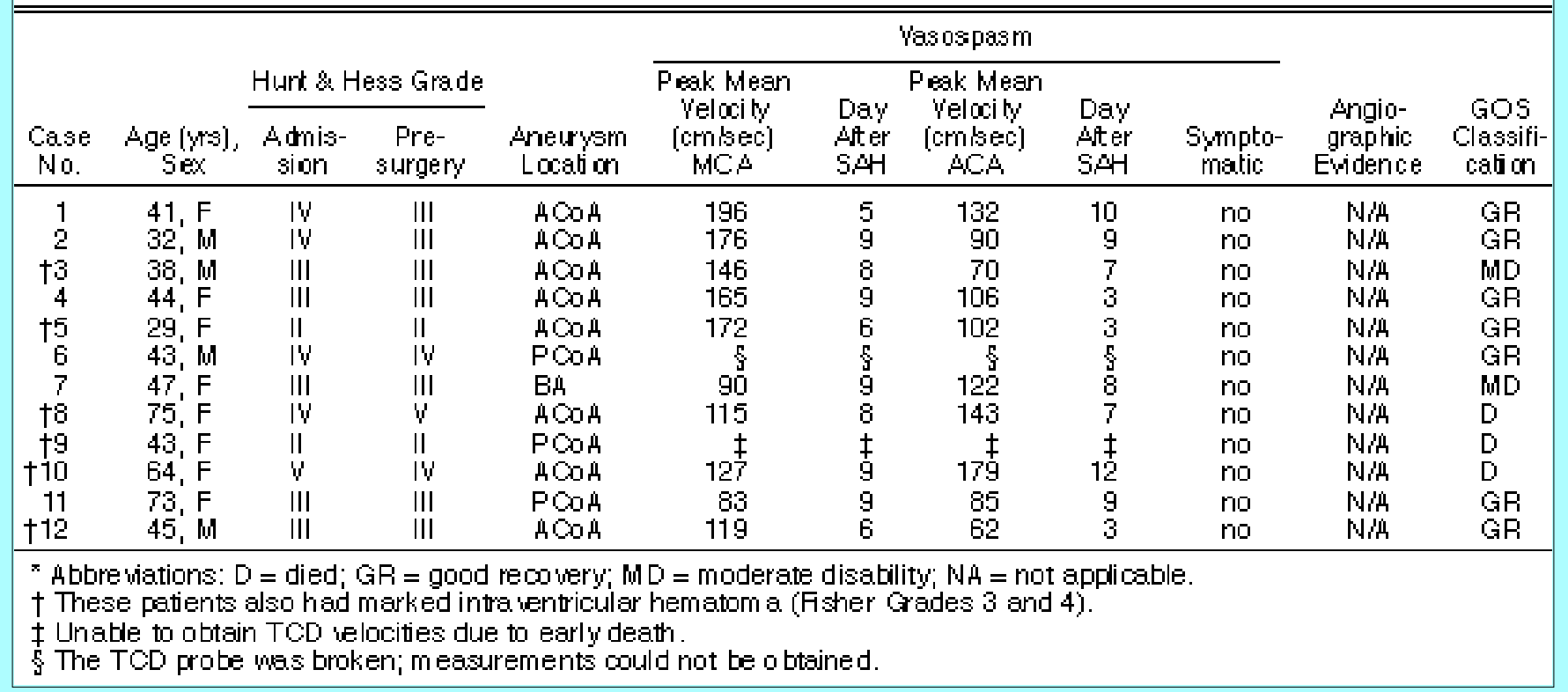

TABLE 3

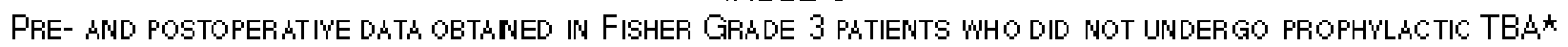

\begin{tabular}{|c|c|c|c|c|c|c|c|c|c|c|c|c|}
\hline \multirow[b]{3}{*}{$\begin{array}{c}\text { Case } \\
\text { No. }\end{array}$} & \multirow[b]{3}{*}{$\begin{array}{c}\text { Age (ys), } \\
\text { Sex }\end{array}$} & & & \multirow{3}{*}{$\begin{array}{l}\text { Aneurysm } \\
\text { Location }\end{array}$} & \multicolumn{6}{|c|}{ Vasospasm } & \multirow[b]{3}{*}{ Reasors $N \alpha$ Included } & \multirow[b]{3}{*}{$\begin{array}{c}\text { GOS } \\
\text { Classifi- } \\
\text { calion }\end{array}$} \\
\hline & & \multicolumn{2}{|c|}{ Hunt \& Hess Grade } & & \multirow{2}{*}{$\begin{array}{c}\text { Peak Mean } \\
\text { Velocity } \\
\text { (cmisec) } \\
\text { MCA }\end{array}$} & \multirow[b]{2}{*}{$\begin{array}{l}\text { Day } \\
\text { Ater } \\
\text { SAH }\end{array}$} & \multirow{2}{*}{$\begin{array}{c}\text { Peak Wean } \\
\text { Velocity } \\
\text { [cmbec] } \\
A C A\end{array}$} & \multirow[b]{2}{*}{$\begin{array}{l}\text { Day } \\
\text { After } \\
S A H\end{array}$} & \multirow[b]{2}{*}{$\begin{array}{l}\text { Sympto- } \\
\text { matic }\end{array}$} & \multirow[b]{2}{*}{$\begin{array}{l}\text { Angio- } \\
\text { graphic } \\
\text { Evidence }\end{array}$} & & \\
\hline & & $\begin{array}{l}\text { Admis- } \\
\text { sion }\end{array}$ & $\begin{array}{l}\text { Pre- } \\
\text { surgery }\end{array}$ & & & & & & & & & \\
\hline 13 & $78, M$ & III & III & POOA & 122 & 3 & 91 & 2 & no & N/A & severe atherosclerosis & $\mathrm{D}$ \\
\hline 14 & $71, \mathrm{~F}$ & $\dddot{y}$ & III & PCOA & 215 & 10 & 198 & 11 & yes & N/A & se vere atherosclerosis & $\mathrm{D}$ \\
\hline 15 & $74, \mathrm{~F}$ & $\mathrm{~V}$ & IV & ACOA & 147 & 5 & & & no & N/A & onl y' 2 wessels treated & $\mathrm{D}$ \\
\hline$\dagger 16$ & $62, \mathrm{~F}$ & II & II & Вй & 135 & 6 & 44 & 4 & yes & yes & early vasospasm & $\bar{v}$ \\
\hline$\dagger \neq 18$ & $69, M$ & v & y & $\mathrm{AOOA}$ & & & & & Yes & Yes & delayed admission & \\
\hline 19 & $40, M$ & II & II & ВĂ & 86 & 5 & 68 & 5 & no & N/A & refused treatment & $\mathrm{GR}$ \\
\hline
\end{tabular}

Of the 12 patients in the study group, there were four men and eight women who ranged in age from 29 to 75 years (mean 48 years). Patients presented with the following Hunt and Hess scores: Grade II (two patients), Grade III (five patients), Grade IV (four patients), and Grade V (one patient). The ruptured aneurysms were located as follows: anterior communicating artery ([ACoA] eight patients), posterior communicating artery ([PCoA] three patients), and BA (one patient). One patient (Case 7) had multiple aneurysms including a ruptured BA aneurysm and a nonruptured PCA aneurysm. Another patient (Case 5) was 37 weeks pregnant at the time of her SAH. After intensive discussion with the obstetric department, which was actively involved in managing her pregnancy, it was decided to allow her to continue with her pregnancy and facilitate normal vaginal delivery after her aneurysm had been surgically treated. Two days after surgery and TBA, continuous fetal monitoring revealed late deceleration, and an uneventful caesarian section was performed.

During the study period, we found two patients (Cases 13 and 14) who were unable to undergo prophylactic TBA because severe atherosclerotic changes made it impossible to perform angioplasty in even one major vessel. These patients were 78 and 71 years old. There were two other patients who underwent prophylactic TBA in only one part of the intracranial circulation, mostly because of severe atherosclerotic changes and vascular abnormalities (Cases 15 and 17). The fact that these patients were also older (74 and 72 years), suggests that this treatment may not be feasible in some patients within this age range. Three patients who presented to our hospital several days after SAH had been either found unresponsive at home or had a delayed referral from an outside facility. One of the patients represented in Table 3 (Case 16), in whom angiography revealed evidence of vasospasm just prior to angioplasty, was excluded from the preventive/prophylactic treatment group. One patient refused to be included in the study (Case 19). The characteristics and treatment results of these patients are summarized in Table 3. 
In the study group the TCD velocities obtained were between 150 and $200 \mathrm{~cm} / \mathrm{seconds}$ in four patients, which was graded as mild vasospasm (Table 1). Blood flow velocities did not exceed $200 \mathrm{~cm} / \mathrm{second}$ (moderate to severe vasospasm). In the exclusion group, mild spasm was encountered in one patient, and one patient was considered to have moderate vasospasm. Because of a temporarily broken probe, a complete TCD examination could not be performed in all patients.

\section{Transluminal Balloon Angioplasty}

As mentioned earlier, four patients had to be excluded from the study group because atherosclerotic changes made angioplasty impossible. Because the same balloon was used to treat different sized vessels, a full angioplasty procedure (angioplasty of all 10 target vessels), could not be performed in any of the patients. Dilation was achieved in $40 \%$ of the $\mathrm{A}_{1}$, all $\mathrm{M}_{1}$, and in $35 \%$ of the $\mathrm{P}_{1}$ segments. Dilation in the ICA and vertebrobasilar arteries (VBAs) was difficult to assess, but the balloon was inflated in $80 \%$ of the supraclinoid ICA segments and in $60 \%$ of the BAs respectively. Unilateral catheterization of a VA was successful in $70 \%$ of the cases. One patient (Case 9) died from rupture of the posterior inferior cerebellar artery during TBA.

\section{Delayed Ischemic Neurological Deficit and Outcome}

No patient in the study group developed DIND. In the exclusion group symptomatic vasospasm occurred in at least two cases.

Based on GOS parameters, outcome assessment in the study group revealed seven patients with good recovery and two patients with moderate disability, for a favorable outcome rate of $75 \%$. Three patients died, one because of vessel rupture during TBA. Two older patients, aged 75 and 64 years, were in very poor clinical condition preoperatively (Hunt and Hess Grades IV-V). Both improved by Day 10: one patient could follow commands and the other had spontaneous eye opening, suggesting no occurrence of clinical vasospasm or DIND, but both later died of pulmonary complications. The moderate disability in patient in Case 3 was due to near-complete kinking of a right $\mathrm{A}_{2}$ segment of the ACA, which was confirmed on postoperative angiography. This caused a mostly left lower-extremity hemiparesis immediately postoperatively, which did not completely resolve. Preoperatively this vessel was already extremely narrow, yet by 6 months the patient made a full recovery. The patient in Case 2 was a police officer, and underwent neuropsychological testing at his work 8 weeks post-SAH; he was found to be fit to resume work.

In the exclusion group two patients had a good recovery, one patient remained vegetative and four patients died. One patient (Case 13) died of pulmonary complications in a supportive nursing facility, and another patient (Case 15) with an extensive medical history of congestive heart failure and rhythm disturbances died of respiratory failure during the course of her hospital stay. Two other patients died and one patient remained in a vegetative state due to occurrence of vasospasm.

\section{DISCUSSION}

Preventing vasospasm with the use of postoperative TBA performed within 3 days of SAH (from a ruptured berry aneurysm) proved to be feasible in this pilot study involving 12 patients. Angioplasty for the treatment of symptomatic vasospasm has been performed by various groups with promising results. In a 10-year review of 224 clinically good-grade patients treated for aneurysmal SAH by Le Roux and colleagues,[28] 39 patients (17.4\%) experienced symptomatic vasospasm; 22 were treated with angioplasty, and 17 were treated without (technique not available). Comparison of these two groups revealed a favorable outcome in $95.5 \%$ of those treated with angioplasty, whereas of those not treated $76.5 \%$ had a favorable outcome. Immediate postoperative TBA had been described earlier by Le Roux and colleagues,[29] but it was not used prophylactically because their patients already had severe angiographically documented vasospasm.

In a similar study with the same enrollment and TCD criteria in which cyclosporine A was used to prevent vasospasm, TCD ultrasonography detected moderate-to-severe spasm in seven (77\%) of nine patients.[31] Five patients (56\%) developed a DIND. Five patients $(56 \%)$ made a good recovery or were moderate disabled. Three patients (33\%) died; all had DINDs, and severe diffuse vasospasm was demonstrated angiographically. In another recent study in which nicardipine was used to prevent vasospasm, placebo-treated patients had TCD-detected moderate-to-severe spasm in $13 \%$ and DINDs in $46 \%$; $56 \%$ made a good recovery, $12 \%$ were moderately disabled, and $18 \%$ died. Vasospasm was identified as a primary cause of death in $4 \%$ of the placebo-treated patients. Overall $11 \%$ of the placebo-treated patients in this study made a less than good recovery because of vasospasm.[16,18] Although the percentages of patient groups with each of the Fisher grades cannot be determined from these publications, patients in all grades were examined in these studies, whereas in our study only patients with extensive SAH were included. In our pilot study no patient had TCD detected moderate-to-severe vasospasm or developed DIND. Nine patients (75\%) had a good recovery or a moderate disability and three patients $(25 \%)$ died: one because of a vessel rupture during TBA and two patients presumably because of the combination of severe initial damage and older age. The aging brain might have a less optimum response to initial bleeding.[26] Patient data obtained from the 12 study patients were compared with a sound, concurrently gathered database for 12 patients having surgery (performed by the senior author). All patients were 
characteristics-matched and managed in a similar fashion. The following data were obtained: four (33\%) of 12 patients developed DINDs, eight patients $(67 \%)$ made a good recovery or were moderately disabled, one patient $(8.3 \%)$ remained in a vegetative state, and three patients $(25 \%)$ died. Of the patients in whom DINDs occurred, two made a good recovery, one died from vasospasm, and one patient remained in a vegetative state; two (17\%) of 12 had an unfavorable outcome due to vasospasm.

Comparison of the data of the previous mentioned published studies and our own characteristics-matched patients with those from this pilot study suggests a much lower incidence of vasospasm in the study group (Table 4). From this small sample size, however, it cannot be determined whether prophylactic TBA is more effective than TBA for symptomatic vasospasm, or if it ultimately leads to better patient outcome.

\begin{tabular}{|c|c|c|c|c|c|}
\hline \multicolumn{6}{|c|}{$\begin{array}{c}\text { TABLE } 4 \\
\text { DELAVED ISCHEMC NEUROLOGICAL DEFC TS AND OUTCOME IN TBA STUDV GROUP COMPARED } \\
\text { WITH EXCLUSION GROUP, RE PORTS FROM THE LITERATURE, AND HISTOR CAL CONTROLS }\end{array}$} \\
\hline Authors \& Year & $\begin{array}{l}\text { Treatmerti } \\
\text { Type of Group }\end{array}$ & $\begin{array}{l}\text { No. of } \\
\text { Patierts }\end{array}$ & $\begin{array}{l}\text { Range } \\
\text { of Fisher } \\
\text { Grades }\end{array}$ & $\begin{array}{l}\text { DIND } \\
(\%)\end{array}$ & $\begin{array}{l}\text { Favorable } \\
\text { Outcome }\end{array}$ \\
\hline $\begin{array}{l}\text { Haley et al., } 1983 \\
\text { Manno, et al., } 1997 \\
\text { present study }\end{array}$ & $\begin{array}{l}\text { nicardipine } \\
\text { cyclosporine } \\
\text { TBג } \\
\text { exdusion } \\
\text { historical controls }\end{array}$ & $\begin{array}{r}457 \\
9 \\
12 \\
7 \\
12\end{array}$ & $\begin{array}{c}\text { all } \\
3 \\
3,3 \& 4 \\
3,3 \& 4 \\
3,3 \& 4\end{array}$ & $\begin{array}{r}46 \\
56 \\
0 \\
43 \\
33\end{array}$ & $\begin{array}{l}56 \\
56 \\
75 \\
29 \\
67\end{array}$ \\
\hline
\end{tabular}

The time window and best technique (degree and duration of dilation) for preventive TBA to be effective cannot be established from our study. In the experimental study by Megyesi et al.,[33] the vessels were dilated to a mean of $166 \%$ of baseline (range 148-200\%) just before the placement of the blood clot, and on Day 7 the vessels were still at $164 \%$ of baseline. In our study TBA was performed much later, and because we used the same balloon for all vessels, we encountered difficulties in entering some of them. Significant dilation was performed in $40 \%$ of the $A_{1}$ and $A_{2}$ segments and $100 \%$ of the $M_{1}$ and $35 \%$ of the $P_{1}$ segments, whereas dilation in the ICAs and VBAs was hardly measurable. Moreover, in the experimental study each segment was dilated twice for 10 seconds, whereas we dilated only once for 5 seconds as we usually do for the treatment of clinical vasospasm.[14] Any of these technical differences, alone or in combination, could be responsible for our finding of a certain degree of TCD velocity increase occurring in most patients between Days 5 and 10 post-SAH, whereas in the experimental canine study of Megyesi, et al., dilation well over baseline was maintained. Species differences or the lesser severity of the experimental SAH compared with clinical aneurysmal SAH (none of the dogs with the untreated vessels with a diameter of $69 \%$ of baseline on Day 7 developed neurological deficits) could also account for the seemingly greater efficacy under experimental conditions.

We aimed at performing TBA in no fewer than 10 vessels (one VA, the BA, both $\mathrm{P}_{1}$ segments of the PCA, bilateral ICAs and $M_{1}$ segments of the MCA's and $A_{1}$ segments of the ACAs), but this goal could not be achieved in a single case. With the flow-directed system we used it was often very difficult or impossible to get into the $A_{1}$ segments because of the take-off angle from the carotid arteries. Using a guided wire system can solve this problem.

Another frequently encountered problem was severe atherosclerosis or vessel tortuosity in older patients that precluded navigating the balloon into either none or one of the three parts of the intracranial circulation (as specified by our protocol). In view of the preliminary nature of our study, we did not believe that overly aggressive attempts to dilate the intracranial vessels could be justified, but considering the encouraging results of this study and the high incidence of poor outcome due to vasospasm in the elderly,[26,34] a more persistent attitude seems warranted.

The most severe and clinically relevant vasospasm seems to occur in the system with the ruptured aneurysm.[41] Thus, it might be sufficient to dilate only the right ICA and right $\mathrm{M}_{1}$ (and perhaps $\mathrm{M}_{2}$ ) segment for a ruptured right-sided MCA aneurysm, or the right ICA $\mathrm{A}_{1}$ (and perhaps $\mathrm{A}_{2}$ ) segment for an ACoA aneurysm with a dominant right $\mathrm{A}_{1}$, or only the VBA system for posterior circulation aneurysms, and so on. As it happened, five of our study patients with ACoA aneurysms had both of their $\mathrm{A}_{2}$ segments filling from a single left $\mathrm{A}_{1}$ segment through the ACoA preoperatively. In some cases we succeeded in dilating the ACoA with the clip on the aneurysm in situ, despite observing a certain degree of clip movement during this maneuver. In these cases the operating surgeon believed that the clip was secure enough in place so as not to jeopardize the patient, but whether this is necessary can only be determined in a much larger study.

In our series of 12 patients, one suffered a fatal complication from TBA. Transluminal balloon angioplasty carries risks because of both the angiographic technique and the actual dilation. From a retrospective study of 597 diagnostic angiograms obtained 
after aneurysm surgery, it was concluded that postoperative angiography is safe and should be routinely performed.[27] The few complications encountered in this large series of patients included groin hematoma, catheter-related spasm, and vessel dissection. The highest reported mortality rate from TBA associated with vessel rupture, and derived from a large series of patients, is 4\%.[8] In one of our patients the posterior inferior cerebellar artery ruptured with balloon inflation in what was presumed to be the BA. Most likely, the patient, who was awake, had shifted somewhat and made the road map no longer correspond with the actual position of the balloon. To ensure that the road map is corresponding to the actual position of the balloon at the time of inflation, we now perform TBA, as do most other centers, only in paralyzed, anesthetized patients.[5,6,8] Thus, an additional advantage of TBA immediately following surgery is that the patient does not need to be reintubated for this procedure, and additonally, the femoral sheath can be left in place from the preoperative angiography.

Despite the abovementioned complication, the results described here are encouraging. Whether prophylactic TBA is efficacious enough to justify the risks and whether the costs of this treatment in all patients are off-set by great savings in some patients can only be determined in a much larger randomized study in patients with Fisher Grades 2 and 3 SAH. Such a study is presently under design.

\section{References}

1. Allen GS, Ahn HS, Preziosi TJ, et al: Cerebral arterial spasm--a controlled trial of nimodipine in patients with subarachnoid hemorrhage. N Engl J Med 308:619-624, 1983

2. Andrews PJ, Piper IR, Dearden NM, et al: Secondary insults during intrahospital transport of head-injured patients. Lancet 335:327-330, 1990

3. Asano T, Takakura K, Sano K, et al: Effects of a hydroxyl radical scavenger on delayed ischemic neurological deficits following aneurysmal subarachnoid hemorrhage; results of a multicenter, placebo-controlled double-blind trial. J Neurosurg 84:792-803, 1996

4. Barnwell SL, Higashida RT, Halbach VV, et al: Transluminal angioplasty of intracerebral vessels for cerebral arterial spasm: reversal of neurological deficits after delayed treatment. Neurosurgery 25:424-429, 1989

5. Bejjani GK, Bank WO, Olan WJ, et al: The efficacy and safety of angioplasty for cerebral vasospasm after subarachnoid hemorrhage. Neurosurgery 42:979-987, 1998

6. Coyne TJ, Montanera WJ, Macdonald RL, et al: Percutaneous transluminal angioplasty for cerebral vasospasm after subarachnoid hemorrhage. Can J Surg 37:391-396, 1994

7. Elliott JP, Newell DW, Lam DJ, et al: Comparison of balloon angioplasty and papaverine infusion for the treatment of vasospasm following aneurysmal subarachnoid hemorrhage. J Neurosurg 88:277-284, 1998

8. Eskridge JM, Song JK: A practical approach to the treatment of vasospasm. AJNR 18:1653-1660, 1997

9. Findlay JM, Kassell NF, Weir BKA, et al: A randomized trial of intraoperative, intracisternal tissue plasminogen activator for the prevention of vasospasm. Neurosurgery 37:168-178, 1995

10. Findlay JM, Weir BKA, Kassell NF, et al: Intracisternal recombinant tissure plasminogen activator after subrachnoid hemorrhage. J Neurosurg 75:181-188, 1991

11. Firlik AD, Kaufmann AM, Jungreis CA, et al: Effect of transluminal angioplasty on cerebral blood flow in the management of symptomatic vasospasm following aneurysmal subarachnoid hemorrhage. J Neurosurg 86:830-839, 1997

12. Fisher CM, Kistler JP, Davis JM: Relation of cerebral vasospasm to subarachnoid hemorrhage visualized by computerized tomographic scanning. Neurosurgery 6:1-9, 1980

13. Fujii Y, Takahashi A, Ezura M, et al: Balloon angioplasty immediately after surgical clipping for symptomatic vasospasm on admission. Report of four cases. Neurosurg Rev 18:79-84, 1995

14. Fujii Y, Takahashi A, Yoshimoto T: Effect of balloon angioplasty on high grade symptomatic vasospasm after subarachnoid hemorrhage. Neurosurg Rev 18:7-13, 1995

15. Grotenhuis JA: Intracarotid slow bolus injection of nimodipine during angiography for treatment of cerebral vasospasm after SAH. A preliminary report. J Neurosurg 61:231-240, 1984 
16. Haley EC Jr, Kassell NF, Apperson-Hanson C, et al: A randomized, double-blind, vehicle-controlled trial of tirilazad mesylate in patients with aneurysmal subarachnoid hemorrhage: a cooperative study in North America. J Neurosurg 86:467-474, 1997

17. Haley EC Jr, Kassell NF, Torner JC: A randomized controlled trial of high-dose intravenous Nicardipine in aneurysmal subarachnoid hemorrhage. A report of the Cooperative Aneurysm study. J Neurosurg 78:537-547, 1993

18. Haley EC Jr, Kassell NF, Torner JC: A randomized trial of nicardipine in subarachnoid hemorrhage; angiographic and transcranial Doppler ultrasound results. A report of the Cooperative Aneurysm Study. J Neurosurg 78:548-553, 1993

19. Higashida RT, Halbach VV, Cahan LD, et al: Transluminal angioplasty for treatment of intracranial arterial vasospasm. J Neurosurg 71:648-653, 1989

20. Higashida RT, Halbach VV, Dowd CF, et al: Intravascular balloon dilatation therapy for intracranial arterial vasospasm: patient selection, technique, and clinical results. Neurosurg Rev 15:89-95, 1992

21. Jan M, Buchheit F, Tremoulet M: Therapeutic trial of intravenous nimodipine in patients with established cerebral vasospasm after rupture of intracranial aneurysms. Neurosurgery 23:154-157, 1988

22. Jennett B, Bond M: Assessment of outcome after severe brain damage. A practical scale. Lancet 1:480-484, 1975

23. Kassel NF, Haley EC Jr, Apperson-Hansen C, et al: Randomized, double-blind, vehicle-controlled trial of tirilazad mesylate in patients with aneurysmal subarachnoid hemorrhage: a cooperative study in Europe, Australia, and New Zealand. J Neurosurg 84:221-228, 1996

24. Kazner E, Sprung C, Adelt D, et al: Clinical experience with Nimodipine in the prophylaxis of neurological deficits after subarachnoid hemorrhage. Neurochirurgia 28 (Suppl 1): 110-113, 1985

25. Konishi Y, Maemura E, Sato E, et al: A therapy against vasospasm after subarachnoidal haemorrhage: clinical experience of balloon angioplasty. Neurol Res 12:103-105, 1990

26. Lanzino G, Kassell NF, Germanson TP, et al: Age and outcome after aneurysmal subarachnoid hemorrhage: why do older patients fare worse. J Neurosurg 85:410-418, 1996

27. Le Roux PD, Elliot JP, Downey L, et al: Improved outcome after rupture of anterior circulation aneurysms: a retrospective 10-year review of 224 good-grade patients. J Neurosurg 83:394-402, 1995

28. Le Roux PD, Elliot JP, Eskridge JM, et al: Risks and benefits of diagnostic angiography following aneurysm surgery: a retrospective analysis of 597 studies submitted.

29. Le Roux PD, Newell DW, Eskridge J, et al: Severe symptomatic vasospasm: the role of immediate postoperative angioplasty. J Neurosurg 80:224-229, 1994

30. Linskey ME, Horton JA, Rao GR, et al: Fatal rupture of the intracranial carotid artery during transluminal angioplasty for vasospasm induced by subrarachnoid hemorrhage. Case report. J Neurosurg 74:985-990, 1991

31. Manno EM, Gress DR, Ogilvy CS, et al: The safety and efficacy of cyclosporine A in the prevention of vasospasm in patients with Fisher grade 3 subarachnoid hemorrhage: A pilot study. Neurosurgery 40:289-293, 1997

32. Mayberg M, Eskridge J, Newell DW, et al: Angioplasty for symptomatic vasospasm, in Sano K, Takakura K, Kassell NF, et al (eds): Cerebral Vasospasm. Tokyo: University of Tokyo Press, 1990, pp 433-436

33. Megyesi JF, Findlay JM, Vollrath B, et al: In vivo angioplasty prevents the development of vasospasm in canine carotid arteries. Pharmacological and morphological analyses. Stroke 28:1216-1224, 1997

34. Muizelaar JP: Commentary on: in vivo angioplasty prevents the development of vasospasm in canine carotid arteries. Stroke 28:1224, 1997

35. Muizelaar JP, Vermeulen M, van Crevel H, et al: Outcome of aneurysmal subarachnoid hemorrhage in patients 66 years of age and older. Clin Neurol Neurosurg 90:203-207, 1988

36. Newell DW, Eskridge JM, Mayberg MR, et al: Angioplasty for the treatment of symptomatic vasospasm following subarachnoid hemorrhage. J Neurosurg 71:654-660, 1989 
37. Newell DW, Eskridge J, Mayberg M: Endovascular treatment of intracranial aneurysms and cerebral vasospasm. Clin Neurosurg 39:348-360, 1992

38. Petruk KC, West M, Mohr G, et al: Nimodipine treatment in poor-grade aneurysm patients. Results of a multicenter double-blind placebo controlled trial. J Neurosurg 68:505-517, 1988

39. Pickard JD, Murray GD, Illingworth R, et al: Effect of oral Nimodipine on cerebral infarction and outcome after subarachnoid haemorrhage: British aneurysm nimodipine trial. Br Med J 298:636-642, 1989

40. Sasaki T, Ohta T, Kikuchi H, et al: A phase II clinical trial of recombinant human tissue-type plasminogen activator against cerebral vasospasm after subarachnoid hemorrhage. Neurosurgery 35:597-605, 1994

41. Seiler RW, Grolimund P, Aaslid R, et al: Cerebral vasospasm evaluated by transcranial ultrasound correlated with clinical grade and CT-visualized subarachnoid hemorrhage. J Neurosurg 64:594-600, 1986

42. Terada T, Kinoshita Y, Yokote H, et al: The effect of endovascular therapy for cerebral arterial spasm, its limitation and pitfalls. Acta Neurochir 139:227-234, 1997

43. Terada T, Nakamura Y, Yoshida H, et al: Percutaneous transluminal angioplasty for the M2 portion vasospasm following SAH: development of the new microballoon and report of cases. Surg Neurol 39:13-17, 1993

44. Tettenborn D, Dycka J: Prevention and treatment of delayed ischaemic dysfunction in patients with aneurysmal subarachnoid hemorrhage. Stroke 21 (Suppl 12):85-89, 1990

45. Trumble ER, Muizelaar JP, Myseros JS, et al: Coagulopathy with the use of hetastarch in the treatment of vasospasm. J Neurosurg 82:44-47, 1995

46. Volk EE, Prayson RA, Perl J II, et al: Autopsy findings of fatal complication of posterior cerebral circulation angioplasty. Arch Pathol Lab Med 121:738-740, 1997

47. Warren BB, Muizelaar JP, Choi SC: Magnesium's role in cerebral vasospasm and outcome in patients with aneurysmal subarachnoid hemorrage, in Findlay, JM (ed): Cerebral Vasospasm.Amsterdam: Elsevier, 1993 pp 401-404

48. Yasargil MG, Fox JL: The microsurgical approach to intracranial aneurysms. Surg Neurol 3:7-14, 1975

49. Zabramski JM, Spetzler RF, Lee KS, et al: Phase I trial of tissue plasminogen activator for the prevention of vasospasm in patients with subarachnoid hemorrhage. J Neurosurg 75:189-196, 1991

50. Zubkov YN, Nikiforov BM, Shustin VA: Balloon catheter technique for dilatation of constricted cerebral arteries after aneurysmal SAH. Acta Neurochir 70:65-79, 1984

Manuscript received August 17, 1998.

Accepted in final form September 15, 1998.

Address reprint requests to: J. Paul Muizelaar, M.D., Ph.D., Department of Neurological Surgery, University of California Davis, 4860 Y Street, Suite 3740, Sacramento, California 95817. email: J.paul.muizelaar@ucdmc.ucdavis.edu. 